\title{
Diferentes abordagens de ensino para projeção vocal no canto lírico
}

\author{
Different Teaching Approaches for Vocal Projection \\ in Classical Singing
}

\section{Nadja Barbosa de Sousa}

Pontifícia Universidade Católica de São Paulo (PUC-SP), São Paulo, São Paulo, Brasil. nadjacanto@hotmail.com

\section{Marta Assumpção de Andrada e Silva}

Pontifícia Universidade Católica de São Paulo (PUC-SP), São Paulo, São Paulo, Brasil. m.andradaesilva@gmail.com

Resumo: Existem diversas concepções a respeito de como desenvolver a projeção da voz no canto lírico, embora o recurso seja corriqueiramente enfatizado na prática desse estilo. 0 objetivo da presente pesquisa foi o de identificar e analisar as principais formas de abordagem de ensino da projeção vocal no canto lírico, por professores atuantes nessa área. Segundo os participantes da amostra, cinco pontos de abordagem para uma efetiva projeção vocal no canto lírico são os aspectos que envolvem o corpo, a percepção/propriocepção do som, a utilização de imagens na didática e, principalmente, a respiração e a emissão da voz.

Palavras-chave: projeção vocal no canto; voz no canto lírico; professor de canto.

Abstract: There are different views about how to develop vocal projection in classical singing, although this feature is routinely emphasized in the practice of this style of singing. The objective of this research was to analyze different teaching approaches of vocal projection in classical singing, from the perspective of teachers who work in this area. According to the participants, the five aspects that involve body, breath, perception/proprioception, use of images in teaching and production of the voice can base the development of effective vocal projection in classical singing.

Keywords: vocal projection in the singing; voice in classical singing; singing teacher. 
SOUSA, Nadja Barbosa de; ANDRADA E SILVA, Marta Assumpção de. (2016) Diferentes abordagens de ensino para projeção vocal no canto lírico. Ed. por Fausto Borém, Eduardo Rosse e Débora Borburema. Per Musi. n.33. Belo Horizonte: UFMG, n.33, p.130-146.

Data de recebimento: 04/10/2015.

Data de aprovação final: 18/03/2016.

\section{1 - Introdução}

No canto lírico a voz precisa ter projeção para ser considerada funcional segundo ANDRADA E SILVA e DUPRAT (2004) e AMATO (2010). Fica ao encargo do professor a tarefa de nortear o aluno quanto ao uso de estratégias favoráveis para que a voz se projete. Isso acontece porque uma das características desse estilo de canto é a amplificação natural do som, diferentemente do popular, em que a amplificação eletrônica é um recurso obrigatório a ser utilizado pelo cantor. No entanto, existem polêmicas sobre quais caminhos podem embasar o ensino da projeção vocal, pois as perspectivas de trabalho nessa direção divergem entre docentes da área, conforme AMATO (2006).

A partir desse entendimento, questiona-se: quais diretrizes são utilizadas no desenvolvimento da projeção vocal do cantor? Existem pontos comuns nessa prática?

Sabe-se que projeção é a capacidade de alcance da voz no espaço físico em que ela é produzida (ANDRADA E SILVA e DUPRAT, 2004; AMATO, 2010; SATALLOF, 2010). TITZE (2004) enfatizou que esse processo depende das condições acústicas do ambiente. SOUSA, MELLO, FERREIRA e ANDRADA E SILVA (2015) observaram que a projeção vocal pode ser definida como uma efetiva audibilidade da voz que é fruto de ampla ação coordenada entre a postura do cantor, controle da respiração durante a produção do som e a observação de questões estético-musicais do repertório. Os autores BUNCH (2005), MELLO e ANDRADA E SILVA (2008), AMATO (2006) e AMATO (2010) reiteram que é importante destacar que esses aspectos relacionados ao corpo, respiração, emissão e audibilidade da voz não operam de maneira dissociada na produção do som vocal.

ANDRADA E SILVA e DUPRAT (2004). BUNCH (2005), CHRISTIANSENS (2005) e HEMAN-ACKAB (2005) sugerem que a prática de exercícios corporais deve ser 
SOUSA, Nadja Barbosa de; ANDRADA E SILVA, Marta Assumpção de. (2016) Diferentes abordagens de ensino para projeção vocal no canto lírico. Ed. por Fausto Borém, Eduardo Rosse e Débora Borburema. Per Musi. n.33. Belo Horizonte: UFMG, n.33, p.130-146.

adotada como prioridade na preparação do canto e anteceder a atividade vocal, pois o instrumento do cantor é o corpo inteiro, não apenas a laringe. Nesse sentido, ter consciência corporal não apenas liberta o cantor de tensões e vícios posturais desnecessários, mas influencia diretamente na produção do som e no seu resultado, que é a projeção. Um estudo científico constatou melhora na projeção de cantores líricos após eles terem se submetido a um programa de desenvolvimento da coordenação motora e uso de técnicas de relaxamento e alongamento, por exemplo (MELLO e ANDRADA E SILVA, 2008).

Com relação à respiração, esse é também fator que merece destaque na prática vocal do cantor (BUNCH, 2005; LE HUCHE e ALLALI, 2005b). Pesquisas como: THORPE, CALA, CHAPMAN e DAVIS (2001), KIESGEN (2005), KIRKPATRICK (2009), GAVA JÚNIOR, FERREIRA e ANDRADA E SILVA (2010), realizadas na intenção de verificar os efeitos da ativação da musculatura respiratória no canto comprovaram resultados satisfatórios em todos os parâmetros vocais.

Sobre o apoio respiratório, apesar de haver polêmica entre respectivas nomenclaturas e estratégias utilizadas no seu desenvolvimento, há concordância na direção de que o recurso assessora a técnica vocal do cantor (KIESGEN, 2005; LE HUCHE e ALLALI, 2005a; LE HUCHE e ALLALI, 2005b; MALDE, 2009). A ativação do apoio favorece o controle da pressão subglótica, melhora a qualidade de emissão da voz, e aumenta a intensidade da projeção (LE HUCHE e ALLALI, 2005a; LE HUCHE e ALLALI, 2005b).

Segundo MENEZES, DUPRAT e COSTA (2005), uma ampla projeção vocal tem relação direta com a emissão da voz, que pode ser abordada a partir de técnicas articulatórias e de vibração. Essas técnicas equilibram o trabalho entre a fonte glótica e o filtro de ressonância, portanto favorecem o aumento da projeção (MILLER, 2000). A prática de exercícios articulatórios também proporciona ao cantor mínimo esforço durante a emissão, pois descentraliza a sobrecarga de esforço na laringe (SANTOS e ASSENCIOFERREIRA, 2001). 
SOUSA, Nadja Barbosa de; ANDRADA E SILVA, Marta Assumpção de. (2016) Diferentes abordagens de ensino para projeção vocal no canto lírico. Ed. por Fausto Borém, Eduardo Rosse e Débora Borburema. Per Musi. n.33. Belo Horizonte: UFMG, n.33, p.130-146.

O desenvolvimento da projeção pelo viés da propriocepção é outro fator que tem respaldo científico. Desenvolver no cantor a percepção que o mesmo tem da própria voz é uma visão justificada por autores como: PACHECO (2004), REHDER (2004), DILLARD (2005), pelo fato de que inicialmente o som é formulado na mente antes mesmo de ser emitido (BUNCH, 2005; PHILLIPS, 2005). É a propriocepção que torna o cantor conhecedor de suas possibilidades e limites vocais. Dessa forma, se o intérprete adquire esse controle, possivelmente saberá dosar o tipo de projeção adequado a cada ambiente. Tal fator também demanda prática (TITZE, 2004; REHDER, 2004). Um recurso universalmente utilizado na pedagogia do canto para se desenvolver a propriocepção além de outros aspectos vocais é o uso de imagens ilustrativas (DILLARD, 2005; PHILLIPS, 2005). A pesquisa de SOUSA, ANDRADA E SILVA e FERREIRA (2010) mostrou que essa ação é justificada por muitos docentes como meio de facilitar o entendimento dos alunos, quanto aos aspectos técnicos e subjetivos do canto, com relato que as imagens facilitam a compreensão da ressonância e a projeção da voz.

A partir da compreensão de que existem inúmeras estratégias de desenvolvimento da projeção da voz, o objetivo da presente pesquisa foi o de identificar e analisar as principais formas de abordagem de ensino da projeção vocal no canto lírico, por professores de canto atuantes nessa área.

\section{2 - Método}

O presente artigo é parte de uma dissertação já concluída por SOUSA e ANDRADA E SILVA (2010). A pesquisa descritiva e de natureza quanti/qualitativa foi submetida ao Comitê de Ética da Pontifícia Universidade Católica de São Paulo (N 073/2009) e contou com a participação voluntária de 72 professores de canto erudito (51 mulheres e 21 homens), residentes em 14 Estados brasileiros. A faixa etária dos sujeitos da amostra variou entre 23 e 77 anos de idade. 0 tempo de experiência docente entre os participantes da pesquisa variou de 2 a 50 anos de exercício, portanto, distribuiu-se a amostra em três grupos: 2 a 10 de anos de ensino, 11 a 21 e 
SOUSA, Nadja Barbosa de; ANDRADA E SILVA, Marta Assumpção de. (2016) Diferentes abordagens de ensino para projeção vocal no canto lírico. Ed. por Fausto Borém, Eduardo Rosse e Débora Borburema. Per Musi. n.33. Belo Horizonte: UFMG, n.33, p.130-146.

mais de 22 anos como professor de canto. Os sujeitos foram convidados a participar da pesquisa via eletrônica, por meio da snowball technique (técnica de amostragem por meio do processo bola de neve, em que um grupo de sujeitos conhecidos indica outros possíveis participantes e assim a amostra é aumentada a partir da junção desses novos elementos, conforme MARSHALL, 1998).

Foram critérios de inclusão: ser professor atuante de canto erudito, possuir alguma formação na área e ter experiência docente mínima de dois anos.

\section{1 - Procedimentos}

Os participantes responderam a um questionário composto dos campos de caracterização da amostra: idade, sexo, local e Estado de residência, tempo de docência, local de atuação e sete questões abertas, referentes a conhecimentos e abordagens sobre o tema projeção da voz. No presente estudo analisou-se a pergunta: “Como você descreve o seu trabalho com projeção vocal junto aos seus alunos?”.

\section{2 - Análise dos dados}

A análise foi dividida em duas partes. Na primeira, utilizou-se a análise categorial (BARDIN, 1977), após várias leituras das respostas dos sujeitos. As palavras de destaque do texto foram agrupadas por assunto. Quando apareciam palavras/terminologias semelhantes, estas eram elencadas na categoria correspondente ao seu sentido na frase, por exemplo: os termos "relaxamento da musculatura"; "musculatura livre de tensões"; "alinhamento corporal" e outros a estes relacionados originaram a categoria Corpo.

Conforme são apresentados na Figura 1, os dados fornecidos pelos participantes que foram considerados imprescindíveis no desenvolvimento da projeção vocal geraram cinco categorias: Corpo, Respiração, Percepção/Propriocepção, Imagem e Emissão da voz. 


\begin{tabular}{|c|c|}
\hline CATEGORIAS & $\begin{array}{l}\text { TERMOS CORRESPONDENTES ÀS ABORDAGENS COM } \\
\text { PROJEÇÃO VOCAL }\end{array}$ \\
\hline 1.CORPO & $\begin{array}{l}\text { Relaxamento da musculatura; musculatura livre de tensões; } \\
\text { alinhamento corporal; correção de vícios posturais; técnicas } \\
\text { alternativas de relaxamento; posicionamento; percepção da } \\
\text { musculatura abdominal e intercostal. }\end{array}$ \\
\hline 2. RESPIRAÇÃO & $\begin{array}{l}\text { Apoio; respiração } \quad \text { costo-abdominal-diafragmática; } \\
\text { respiração costo-diafragmática; trabalho do suporte de ar; } \\
\text { controle do ar; pressão subglótica; expiração. }\end{array}$ \\
\hline 3. PERCEPÇÃO/PROPRIOCEPÇÃO & $\begin{array}{l}\text { Conscientização; percepção do próprio corpo; percepção da } \\
\text { própria voz; busca de sensações particulares do aluno; } \\
\text { busca de conhecimento da produção da voz; observação a } \\
\text { outros cantores; compreensão de idiomas; respeito aos } \\
\text { limites vocais; observância às diversas técnicas de canto; } \\
\text { conhecimento vocal; paciência; trabalho diário; ausência de } \\
\text { "clichês" da projeção; espaço acústico; sensações no } \\
\text { formante. }\end{array}$ \\
\hline 4. IMAGEM & $\begin{array}{l}\text { Som redondo; na máscara; "chiaro/scuro" sensação de } \\
\text { espaço interno (bocejo); som para cima e para trás; giro } \\
\text { vocal; linha na vertical acima da cabeça; som para "fora da } \\
\text { boca"; canto em direção ao ouvinte; chamamento a alguém } \\
\text { distante; ângulo de } 45 \text { graus (corpo e chão); voz dirigida a } \\
\text { um ponto específico; fundo do palato (duro/mole). }\end{array}$ \\
\hline 5. EMISSÃO DA VOZ & $\begin{array}{l}\text { Vocalizes; consoantes para desenvolver a dicção; extensão } \\
\text { por meio de escalas ascendente e descendente; exercícios de } \\
\text { flexibilidade; dinâmica; fraseado; staccato; legatto; ataque; } \\
\text { máximo rendimento; mínimo esforço; sons nasais; } \\
\text { desenvolvimento da ressonância; corpo da voz; foco; som } \\
\text { como produto final da emissão; controle da qualidade do } \\
\text { som; emissão confortável. }\end{array}$ \\
\hline
\end{tabular}

Figura 1: Quadro das categorias relacionadas às abordagens com a projeção vocal no canto erudito, segundo opinião de 72 professores de canto atuantes no Brasil.

A segunda parte da análise dos dados foi a análise estatística, em que se procedeu com o cruzamento entre as variáveis: sexo, tipos de formação e tempo de experiência docente dos professores e as categorias apresentadas na Figura 1. Estes dados foram comparados entre si.

Para verificar a associação entre as variáveis categóricas, foi empregado o teste de associação qui-quadrado ou teste exato de Fisher (quando pelo menos uma das frequências esperadas foi menor do que 5). Para todos os testes estatísticos foi estabelecido um erro alfa $=5 \%$, isto é, os resultados dos testes foram considerados estatisticamente significativos quando $\mathrm{p}<0,05$. Os testes foram realizados com $\mathrm{o}$ auxílio do software SPSS for Windows, versão 11.0. 


\section{3 - Resultados e discussão}

Na Figura 2 foram apresentadas as categorias relacionadas às diferentes formas de abordagem sobre a projeção vocal, fornecidas pelos 72 professores de canto da amostra.

Com relação ao sexo, maior referência às cinco categorias formuladas foi feita entre as professoras mulheres. Quanto ao tipo de formação, a categoria Corpo foi mais citada entre os sujeitos sem graduação. Os professores graduados e/ou especialistas foram os que mais citaram as categorias Respiração, Percepção/propriocepção, Imagem e Emissão da voz. Referente ao tempo de docência, sujeitos com menor tempo de experiência citaram as cinco categorias. Sujeitos com maior tempo de experiência não fizeram referência à categoria Corpo.

Apesar de registrado o destaque de referência às variáveis, não foi constatada a significância estatística entre as mesmas.

\begin{tabular}{|c|c|c|c|}
\hline Categorias & Não referência n(\%) & Referência n(\%) & Valores de $p$ \\
\hline \multicolumn{4}{|c|}{ CORPO } \\
\hline $\begin{array}{l}\text { Masculino } \\
\text { Feminino }\end{array}$ & $\begin{array}{l}15(71,4) \\
44(86,3)\end{array}$ & $\begin{array}{l}6(28,6) \\
7(13,7)\end{array}$ & 0,180 \\
\hline $\begin{array}{l}\begin{array}{l}\text { Tipo de formação } \\
\text { graduação }\end{array} \\
\\
\begin{array}{r}\text { Graduação/Especialização } \\
\text { Mestrado/Doutorado }\end{array}\end{array}$ & $\begin{array}{l}11(64,7) \\
32(86,5) \\
16(88,9)\end{array}$ & $\begin{array}{l}6(35,3) \\
5(13,5) \\
2(11,1)\end{array}$ & 0,105 \\
\hline $\begin{array}{lr}\begin{array}{lr}\text { Tempo de docência (anos) } \\
10\end{array} & 2- \\
& 11-21 \\
22 \text { ou mais } \\
\end{array}$ & $\begin{array}{c}31(79,5) \\
17(77,3) \\
11(100,0)\end{array}$ & $\begin{array}{c}8(20,5) \\
5(22,3) \\
0(0)\end{array}$ & 0,234 \\
\hline \multicolumn{4}{|c|}{ RESPIRAÇÃO } \\
\hline $\begin{array}{l}\text { Masculino } \\
\text { Feminino }\end{array}$ & $\begin{array}{l}11(52,4) \\
27(52,9)\end{array}$ & $\begin{array}{l}10(47,6) \\
24(47,1)\end{array}$ & 0,965 \\
\hline $\begin{array}{l}\text { Tipo de formação } \\
\text { graduação } \\
\\
\begin{array}{r}\text { Graduação/Especialização } \\
\text { Mestrado/Doutorado }\end{array}\end{array}$ & $\begin{array}{c}8(47,1) \\
24(64,9) \\
6(33,3)\end{array}$ & $\begin{array}{c}9(52,9) \\
13(35,1) \\
12(66,7)\end{array}$ & 0,077 \\
\hline $\begin{array}{lr}\text { Tempo de docência (anos) } & 2- \\
10 & 11-21 \\
& 22 \text { ou mais } \\
\end{array}$ & $\begin{array}{c}20(51,3) \\
11(50,0) \\
7(63,6)\end{array}$ & $\begin{array}{c}19(48,7) \\
11(50,0) \\
4(36,4)\end{array}$ & 0,732 \\
\hline \multicolumn{4}{|c|}{ PERCEPÇÃO/PROPRIOCEPÇÃO } \\
\hline $\begin{array}{l}\text { Masculino } \\
\text { Feminino }\end{array}$ & $\begin{array}{l}15(71,4) \\
34(66,7) \\
\end{array}$ & $\begin{array}{c}6(28,6) \\
17(33,3) \\
\end{array}$ & 0,694 \\
\hline
\end{tabular}


SOUSA, Nadja Barbosa de; ANDRADA E SILVA, Marta Assumpção de. (2016) Diferentes abordagens de ensino para projeção vocal no canto lírico. Ed. por Fausto Borém, Eduardo Rosse e Débora Borburema. Per Musi. n.33. Belo Horizonte: UFMG, n.33, p.130-146.

\begin{tabular}{|c|c|c|c|}
\hline $\begin{array}{l}\begin{array}{l}\text { Tipo de formação } \\
\text { graduação }\end{array} \\
\\
\begin{array}{r}\text { Graduação/Especialização } \\
\text { Mestrado/Doutorado }\end{array}\end{array}$ & $\begin{array}{l}13(76,5) \\
23(62,2) \\
13(72,2)\end{array}$ & $\begin{array}{c}4(23,5) \\
14(37,8) \\
5(27,8)\end{array}$ & 0,525 \\
\hline $\begin{array}{lr}\text { Tempo de docência (anos) } & 2- \\
10 & 11-21 \\
22 \text { ou mais } \\
\end{array}$ & $\begin{array}{c}24(61,5) \\
17(77,3) \\
8(72,7)\end{array}$ & $\begin{array}{c}15(38,5) \\
5(22,7) \\
3(27,3)\end{array}$ & 0,421 \\
\hline \multicolumn{4}{|c|}{ IMAGEM } \\
\hline $\begin{array}{l}\text { Masculino } \\
\text { Feminino } \\
\end{array}$ & $\begin{array}{l}19(90,5) \\
46(90,2) \\
\end{array}$ & $\begin{array}{l}2(9,5) \\
5(9,8) \\
\end{array}$ & 1,000 \\
\hline $\begin{array}{l}\begin{array}{l}\text { Tipo de formação } \\
\text { graduação }\end{array} \\
\\
\begin{array}{r}\text { Graduação/Especialização } \\
\text { Mestrado/Doutorado }\end{array} \\
\end{array}$ & $\begin{array}{l}15(88,2) \\
33(89,2) \\
17(94,4)\end{array}$ & $\begin{array}{c}2(11,8) \\
4(10,8) \\
1(5,6)\end{array}$ & 0,784 \\
\hline $\begin{array}{lr}\text { Tempo de docência (anos) } & 2- \\
10 & 11-21 \\
& 22 \text { ou mais }\end{array}$ & $\begin{array}{c}36(92,3) \\
20(90,9) \\
9(81,8)\end{array}$ & $\begin{array}{c}3(7,7) \\
2(9,1) \\
2(18,2)\end{array}$ & 0,580 \\
\hline \multicolumn{4}{|c|}{ EMISSÃO DA VOZ } \\
\hline $\begin{array}{l}\text { Masculino } \\
\text { Feminino }\end{array}$ & $\begin{array}{c}6(28,6) \\
18(35,3)\end{array}$ & $\begin{array}{l}15(71,4) \\
33(64,7)\end{array}$ & 0,582 \\
\hline $\begin{array}{l}\text { Tipo de formação } \\
\text { graduação } \\
\\
\begin{array}{r}\text { Graduação/Especialização } \\
\text { Mestrado/Doutorado }\end{array} \\
\end{array}$ & $\begin{array}{c}6(35,3) \\
13(35,1) \\
5(27,8)\end{array}$ & $\begin{array}{l}11(64,7) \\
24(64,9) \\
13(72,2)\end{array}$ & 0,846 \\
\hline $\begin{array}{lr}\text { Tempo de docência (anos) } & 2- \\
10 & 11-21 \\
& 22 \text { ou mais }\end{array}$ & $\begin{array}{c}12(30,8) \\
8(36,4) \\
4(36,4)\end{array}$ & $\begin{array}{c}27(69,2) \\
14(63,6) \\
7(63,6)\end{array}$ & 0,882 \\
\hline
\end{tabular}

Figura 2: Tabela de distribuição da amostra, em número e porcentagem, segundo sexo, formação, tempo de docência e referência às categorias corpo, respiração, percepção/propriocepção, imagem e emissão (n=72).

Em relação ao tema central do estudo, é importante refletir sobre a dificuldade que alguns participantes demonstraram em falar sobre sua prática, quando foram requisitados a responder à pergunta: “Como você descreve o seu trabalho com projeção vocal junto aos seus alunos?". Há que se considerar que, fornecer descrição de uma prática é tarefa difícil para qualquer profissional e isso independe da formação acadêmica. Essa constatação pode conduzir à reflexão de que descrever uma prática tem associação com a didática do professor e sua relação com o aluno. A proposta da pesquisa não foi a de retratar esse aspecto, mas cabe pontuar que, em qualquer área, a arte do ensino demanda uma relação de troca (FALSARELLA, 2004). Não se deve estabelecer uma hierarquia diante do aluno e desconsiderar a bagagem trazida por ele, pois isso pode limitar e comprometer a didática. Ademais, o aluno não será 
SOUSA, Nadja Barbosa de; ANDRADA E SILVA, Marta Assumpção de. (2016) Diferentes abordagens de ensino para projeção vocal no canto lírico. Ed. por Fausto Borém, Eduardo Rosse e Débora Borburema. Per Musi. n.33. Belo Horizonte: UFMG, n.33, p.130-146.

adequadamente formado, pois o papel do educador transcende os limites de informar. Diante dessa compreensão, deve-se alertar o professor para a importância de refletir sobre sua didática. Especificamente no canto, temática do presente estudo, vale ressaltar que, para firmar a técnica vocal do cantor é preciso, além de conhecimento, abertura por parte do docente. Valorizar e considerar o que o aluno traz e estabelecer a troca de bagagens pode contribuir nas abordagens e práticas de ensino (FALSARELLA, 2004).

Apesar de não ter sido constatada significância estatística $(\mathrm{p}<0,05)$ nas referências dos participantes às categorias, os resultados obtidos após o cruzamento entre as variáveis merecem discussão.

Conforme é exposto na Figura 2, a primeira categoria apresentada sobre diferentes formas de abordagem foi a denominada Corpo, fato que indica ser o corpo um dos fatores aliados ao desenvolvimento da projeção vocal do cantor. Cabe pontuar que esse achado teve respaldo nos autores BUNCH (2005), HEMAN-ACKAB (2005), LE HUCHE e ALLALI (2005b), MELLO e ANDRADA E SILVA (2008), MELLO, BALLESTERO e ANDRADA E SILVA (2015).

Os professores sem graduação foram os que mais mencionaram o corpo como forma de se abordar a projeção da voz, em comparação aos demais grupos, fato que chamou atenção. Entende-se que o corpo, por si só, denuncia tensões exacerbadas e vícios posturais, o que faz com que o senso comum de percepção seja suficiente para corrigi-los. Portanto, o professor saberá pedir, quando necessário, que o aluno levante ou abaixe a cabeça, não olhe para o chão, relaxe os ombros, não cante encurvado e fatores correspondentes. Por sua vez, pode ser que professores com mestrado/doutorado recebam mais comumente alunos com bagagem técnica e estágio avançado em canto e tenham o corpo minimamente trabalhado. Sendo assim, de início, o foco do docente graduado talvez não seja o corpo, a menos que o aluno apresente uma alteração que comprometa consideravelmente o funcionamento da voz. 
SOUSA, Nadja Barbosa de; ANDRADA E SILVA, Marta Assumpção de. (2016) Diferentes abordagens de ensino para projeção vocal no canto lírico. Ed. por Fausto Borém, Eduardo Rosse e Débora Borburema. Per Musi. n.33. Belo Horizonte: UFMG, n.33, p.130-146.

Na Figura 2, a segunda categoria apresentada foi a da Respiração. Para alguns autores, como SONNINEN, LAUKKANEN, KARMA, HURME (2005) e CHRISTIANSENS (2005) corpo e respiração estão intricados em uma só unidade. Da mesma forma, para BUNCH (2005), respiração no canto resulta da ação conjunta com a postura corporal. A mesma reitera que, para se manter a sustentação dos tons, pressão constante do ar e duração das frases musicais representam equilíbrio dinâmico entre ação muscular e alinhamento corporal. Em outras pesquisas, THORPE, CALA, CHAPMAN e DAVIS (2001), PETERSEN e WESTGAARD (2003), SONINEN, LAUKKANEN, KARMA, HURME (2005), KIESGEN (2005), a opinião de que esse aspecto é o ponto de partida para desenvolvimento da projeção vocal foi enfatizada.

No caso dos participantes do presente estudo, houve afirmações que claramente apontaram que, não apenas a projeção, como também o ensinamento de toda a técnica vocal deveria se iniciar por respiração, sobretudo no aspecto do apoio. Este pensamento pode ser ilustrado na fala do participante [S11]: “O primeiro passo para a projeção vocal com qualidade é trabalhar exaustivamente o apoio do diafragma. É ele que, na minha opinião, suporta toda a técnica vocal (...)”. 0 participante [S14] concordou: “(...) para se conseguir uma maior projeção vocal é fundamental a plena consciência do posicionamento do diafragma, como ponto de partida do som e apoio da $\operatorname{voz}(\ldots) "$

Há que se considerar que existe grande variedade de terminologias referentes à respiração. Pode-se usar este argumento para entender porque os professores com mestrado/doutorado e com certo tempo na docência destacaram a respiração como um dos fatores que mais merecem atenção na abordagem com a projeção vocal. Por isso, considera-se que é árdua a tarefa do professor em trabalhar a respiração do aluno em meio a uma variedade de termos que, por vezes, confundem o entendimento do cantor (KIESGEN, 2005; GAVA JÚNIOR, FERREIRA e ANDRADA E SILVA, 2010). Para tanto, o profissional deverá romper as barreiras e nortear o aluno, e assim firmar suas técnicas. E, se para o docente, trabalhar a respiração é difícil, associá-la à projeção é algo ainda mais minucioso, que, sem dúvida, remete a conhecimento específico e aprofundado. Ao mesmo tempo, pode ser que, na visão 
SOUSA, Nadja Barbosa de; ANDRADA E SILVA, Marta Assumpção de. (2016) Diferentes abordagens de ensino para projeção vocal no canto lírico. Ed. por Fausto Borém, Eduardo Rosse e Débora Borburema. Per Musi. n.33. Belo Horizonte: UFMG, n.33, p.130-146.

deste professor, se o aluno conseguir entender e utilizar-se do mecanismo respiratório, durante a fonação, será bem sucedido no desenvolvimento de outros aspectos do canto. A partir desta suposição, entende-se que o respaldo científico pode auxiliar não apenas o docente, como também ser um recurso fundamental na didática da emissão cantada.

Ainda conforme a Figura 2 formulou-se a categoria de Percepção/propriocepção como outra forma de abordagem da projeção vocal. Os autores REHDER (2004), DILLARD (2005), PHILLIPS (2005), também salientaram a imprescindibilidade de desenvolvimento da percepção e propriocepção do cantor com relação à sua voz e os resultados almejados durante o canto. Cabe ao professor de canto acompanhar o progresso vocal dos alunos, desenvolver esse potencial, e somado a isso, nortear o pupilo no equilíbrio entre emoção e técnica, por meio da autonomia da propriocepção (DILLARD, 2005). É esta capacidade que propicia ao cantor se concentrar no funcionamento da voz como um todo, sem comprometer a interpretação e expressividade, e sem alterar a qualidade da projeção vocal. Pode-se referir ao desenvolvimento da propriocepção como o aspecto que mais exige paciência do docente, pois tal trabalho exige disponibilidade do profissional, bem como tempo, criatividade, e, sobretudo, que este seja paciente (PHILLIPS, 2005). Em confirmação a esta suposição, o participante [S51] citou: “(...) meu trabalho é fruto de muita paciência. Não se consegue uma projeção em pouco tempo (...)”. Se as estratégias criadas para auxiliar o aluno não forem suficientes e não apresentarem resultados satisfatórios, o professor precisará buscar novos caminhos para atender à demanda do cantor. A criatividade requer conhecimento (PHILLIPS, 2005). 0 fato de os sujeitos da graduação/especialização estarem em constante reflexão e em contato com novas discussões pode ser um forte aliado nessa busca.

A penúltima categoria de abordagem formulada a partir das respostas dos participantes foi a das Imagens (Figura 2). A partir desse achado, sobre o uso de imagens na pedagogia vocal cantada, vale pontuar que esse é um recurso universalmente utilizado por profissionais do canto, de diferentes estilos e gêneros musicais. Esse pensamento foi corroborado nas pesquisas de MALDE (2009) e SOUSA, 
SOUSA, Nadja Barbosa de; ANDRADA E SILVA, Marta Assumpção de. (2016) Diferentes abordagens de ensino para projeção vocal no canto lírico. Ed. por Fausto Borém, Eduardo Rosse e Débora Borburema. Per Musi. n.33. Belo Horizonte: UFMG, n.33, p.130-146.

ANDRADA E SILVA e FERREIRA (2010), como meio eficaz de se traduzir a complexidade de termos específicos referentes à fisiologia da voz e aos aspectos técnicos do canto. $\mathrm{O}$ fato de o professor ter conhecimento científico não significa que deva restringir a didática e linguagem apenas aos termos científicos. Isso pode não ser viável para o aluno, inclusive para o iniciante, uma vez que o canto é arte, portanto, subjetivo, em uma posição oposta à ciência. Cabe ao professor dosar os termos conforme a demanda do cantor e entender que a linguagem por meio de expressões metafóricas pode ampliar o leque de recursos didáticos.

O fato de a referência ao uso das imagens na didática ter sido mais enfatizada na opinião dos sujeitos sem graduação, da presente amostra, conduz à reflexão de que há forte tendência a se acreditar que professores não graduados sempre se utilizam do conhecimento empírico, e que, por sua vez, os graduados recorram apenas ao conhecimento científico em sua pedagogia. No entanto, pondera-se que a imagem é facilitadora para o aluno perceber aspectos específicos da voz ou de técnicas de canto, independentemente se o professor possui conhecimento teórico apurado ou não (SOUSA, ANDRADA E SILVA e FERREIRA, 2010). Ressaltata-se que, se o recurso das metáforas auxilia a compreensão do aluno, e se o professor for aberto a esse entendimento, não hesitará em se utilizar das ilustrações na abordagem. Não obstante ao fato de que o canto é uma arte subjetiva e que as ilustrações conduzem o cantor à rápida abstração da arte, o professor deve escolher diferentes imagens a utilizar com cada aluno. As imagens tanto podem auxiliar a compreensão do intérprete, quanto trazer problemas quando interpretadas erroneamente (MALDE, 2009). Dessa forma, é necessário cautela na escolha das ilustrações, uma vez que as sensações de cada indivíduo são muito pessoais (MALDE, 2009).

Por último, a Figura 2 apresentou a última categoria: Emissão da voz. A opinião dos professores da amostra em abordar a projeção vocal por meio de aspectos relacionados ao modo como se emite o som também encontrou respaldo em pesquisas e em literatura (SANTOS e ASSENCIO-FERREIRA, 2001; ANDRADA E SILVA e DUPRAT, 2004; HEMAN-ACKAB, 2005; AMATO, 2006). Os autores reiteraram que o canto, em geral, é resultado da ação conjunta entre corpo, respiração e emissão do 
SOUSA, Nadja Barbosa de; ANDRADA E SILVA, Marta Assumpção de. (2016) Diferentes abordagens de ensino para projeção vocal no canto lírico. Ed. por Fausto Borém, Eduardo Rosse e Débora Borburema. Per Musi. n.33. Belo Horizonte: UFMG, n.33, p.130-146.

som vocal. Esses fatores não operam de maneira independente, mas em conjunto, o que pode ser entendido como coordenação pneumofonoarticulatória (MELLO e ANDRADA E SILVA, 2008).

De acordo com os sujeitos da pesquisa, a emissão pode ser trabalhada a partir de vocalizes que contemplem o desenvolvimento de: ressonância, dicção, articulação e aspectos musicais, como dinâmica (sons forte/piano), fraseado, legatto, staccato, entre outros. Aliada a esses fatores trabalha-se também a ação do corpo e da respiração. 0 destaque dado à presente categoria suscita o entendimento de que não basta ao cantor ter consciência fragmentada dos aspectos participantes na produção da voz cantada, mas saber coordená-los ao emitir o som. Nessa direção, ao se dispensar atenção aos elementos atuantes na emissão pode-se obter resultados satisfatórios no tipo de projeção almejado pelo cantor (MILLER, 2000; ANDRADA E SILVA e DUPRAT, 2004; REHDER, 2004).

A partir dos achados da pesquisa, verificou-se que as duas categorias mais citadas entre os participantes foram Respiração e Emissão da voz. Frases extraídas das respostas dos sujeitos do estudo ilustram essas evidências. Com relação à respiração, o S22 citou: "Primeiramente explico ao aluno o mecanismo respiratório. Trabalho muito a respiração de apoio, pois uma boa projeção depende do controle da entrada e saída do ar (...)". O S39 afirmou: "A projeção vocal juntamente com o trabalho respiratório constituem-se, na minha opinião, a base do trabalho vocal (...)". Com relação às abordagens por meio da emissão do som, afirmou-se: “(...) cada aluno deverá descobrir com o auxílio do professor o uso das técnicas de ressonância, como aprender a projetar a sua voz de uma maneira agradável e sem esforço e com qualidade” [S8]. Citou o S4: “(...) trabalho a conscientização e adequação de (...) fonação, configuração do trato vocal, ressonância, articulação, pitch e volume (...)". 


\section{4- Considerações finais}

Segundo os professores de canto entrevistados no estudo, as principais formas de se alcançar uma projeção vocal efetiva no canto lírico são os métodos que envolvem: alinhamento corporal, desenvolvimento da propriocepção do cantor, utilização de imagens que facilitam a compreensão de termos utilizados na pedagogia do canto e, principalmente, exercícios que coordenam respiração e emissão da voz. Ressalta-se que cada professor deve encontrar sua didática de trabalho conforme os objetivos e demandas dos alunos. Contudo, as diretrizes que foram apontadas nesta pesquisa e respaldadas na literatura podem nortear o ensino desse aspecto tão subjetivo no canto, que é a projeção da voz.

\section{Agradecimento}

À Coordenação de Aperfeiçoamento de Pessoal e Nível Superior (CAPES), pelo suporte financeiro durante o desenvolvimento da pesquisa (2009/2010).

\section{Referências}

1. AMATO, R.C.F. (2010). Manual de saúde vocal: teoria e prática da voz falada para professores e comunicadores. São Paulo: Editora Atlas S.A.

2. (2006) Um estudo sobre a emissão cantada e falada de vogais em cantores líricos brasileiros. In: Anais do XVI Congresso da Associação Nacional de Pesquisa e Pós-Graduação em Música (ANPPOM), Brasília. Disponível em:<http://www.anppom.com.br/anais/anaiscongresso anppom 2006/CDROM/CO M/06 Com Perf/sessao02/06COM Perf 0202-049.pdf> Acesso em: 01/06/2010.

3. ANDRADA E SILVA, M.A.de; DUPRAT, A.C. (2004). Voz cantada. In: FERREIRA, Léslie Piccolotto, organizadora. Tratado de Fonoaudiologia. São Paulo: Rocca.

4. BARDIN, L. (1977). L'Analyse de Contenu. RETO, Luís Antero e PINHEIRO, Augusto, tradutores. Presses Universitaires de France.

5. BUNCH, M. (2005). The performer's voice: realizing your vocal potential. New York: Norton \& Co. 
SOUSA, Nadja Barbosa de; ANDRADA E SILVA, Marta Assumpção de. (2016) Diferentes abordagens de ensino para projeção vocal no canto lírico. Ed. por Fausto Borém, Eduardo Rosse e Débora Borburema. Per Musi. n.33. Belo Horizonte: UFMG, n.33, p.130-146.

6. CHRISTIANSEN, L. (2005). Messa di voce and dynamic control. Journal of Singing. n.3, v.61, p.269-270.

7. DILLARD, J. (2005). Teaching teachers of singing. Journal of Singing. n.2, v.62, p.125-126.

8. FALSARELLA, A.M. (2004). Formação continuada e prática de sala de aula: os efeitos da formação continuada na atuação do professor. Campinas: Autores Associados.

9. GAVA JUNIOR, W.; FERREIRA, L. P.; ANDRADA E SILVA, M.A. de. (2010). Apoio respiratório na voz cantada: perspectiva de professores de canto e fonoaudiólogos. São Paulo: Rev. CEFAC. n.12, v.4, p.317-328.

10. HEMAN-ACKAB, Y. (2005). Physiology of voice production: considerations for the vocal performer. Journal of Singing. n.2, v.62, p.173-176.

11. KIESGEN, P. (2005). Breathing. Journal of Singing. n.2, v.62, p.169-171.

12. KIRKPATRICK, A. (2009). Chiaroscuro and the quest for optimal resonance. Journal of Singing. n.1, v.66, p.15-21.

13. LE HUCHE, F.; ALLALI, A. (2005a). A voz: anatomia e fisiologia dos órgãos da voz e da fala. LOGUERCIO, Sandra, tradutora. $3^{\text {a. }}$ ed. Porto Alegre: Artmed. v.1.

14. (2005b). A voz: tratamento dos distúrbios vocais. LOGUERCIO, Sandra, tradutora. 3 $3^{\text {a. }}$ ed. Porto Alegre: Artmed, v.4.

15. MARSHALL G. (1998). Snowballing technique. A Dictionary of Sociology. New York: Oxford University Press.

16. MALDE, M. (2009). Mapping the structures of resonance. Journal of Singing. n.5, v.65, p.521-529.

17. MELLO, E.L.; ANDRADA E SILVA, M.A. de. (2008). 0 corpo do canto: alongar, relaxar ou aquecer? São Paulo: Rev. CEFAC. n.4, v.10, p.548-556.

18. MELLO, E.L.; BALLESTERO, L.R.B.; ANDRADA E SILVA, M.A. de. (2015). Postura corporal, voz e autoimagem em cantores líricos. Revista Per Musi. n.31, p.74-85.

19. MENEZES, M.; DUPRAT, A. C.; COSTA, H. O. (2005). Vocal and laryngeal effects of voiced tongue vibration: Technique according to performance time. Journal of Voice. n.1, v.19, p.61-70.

20. MILLER, R. (2000). Training Soprano Voices. New York: Oxford University Press. 21. (2004). Solutions for singers. New York: Oxford University Press. 
SOUSA, Nadja Barbosa de; ANDRADA E SILVA, Marta Assumpção de. (2016) Diferentes abordagens de ensino para projeção vocal no canto lírico. Ed. por Fausto Borém, Eduardo Rosse e Débora Borburema. Per Musi. n.33. Belo Horizonte: UFMG, n.33, p.130-146.

22. PACHECO, A. (2004). Mudanças na prática vocal da escola italiana de canto: uma análise comparativa dos tratados de canto de Píer Tosi, Giambattista Mancini e Manuel Garcia. Campinas: Universidade Estadual de Campinas. [Dissertação de Mestrado].

23. PETTERSEN, V.; WESTGAARD, R. (2003). The association between upper trapezius activity and thorax movement in classical singing. Journal of Voice. n.4, v.18, p.500-512.

24. PHILLIPS, G. (2005). Singing, creativity and courage. Journal of Singing. n.2, v.62, p.159-165.

25. REHDER, M.I. (2004). Inter-relações entre voz e motricidade oral. In: FERREIRA, Léslie Piccolotto., organizadora. Tratado de Fonoaudiologia. São Paulo: Roca. p.59-64.

26. SANTOS, F.M.R.; ASSENCIO-FERREIRA, V.J. (2001). Técnicas fonoarticulatórias para o profissional da voz. São Paulo: Rev. CEFAC. n.1, v.3, p.53-64.

27. SATALOFF, R.T. (2010). Acoustics: what we need to know about our environment. Journal of Singing. n.4, v.66, p.429-431.

28. SONNINEN, A.; LAUKKANEN, A.M.; KARMA; HURME, P. (2005). Evaluation of support in singing. Journal of Voice. n.2, v.19, p.223-237.

29. SOUSA, N.B.de; ANDRADA E SILVA, M.A. de. (2010). Projeção vocal: conhecimentos e abordagens na perspectiva de professores de canto erudito. São Paulo: Pontifícia Universidade Católica de São Paulo. [Dissertação de Mestrado em Fonoaudiologia].

30. SOUSA, N.B.de; MELLO, E.L.; FERREIRA, L.P.; ANDRADA E SILVA, M.A. de. (2015). Projeção vocal na opinião de professores de canto lírico. Revista Distúrbios da Comunicação. n.3, v.27, p.520-529.

31. SOUSA, J.M.; ANDRADA E SILVA, M.A. de; FERREIRA, L.P. (2010). 0 uso de metáforas como recurso didático no ensino do canto: diferentes abordagens. São Paulo: Rev. Sociedade Brasileira de Fonoaudiologia. n.3, v.15, p.317-328.

32. THORPE, W.; CALA, S.; CHAPMAN, J.; DAVIS, P. (2001). Patterns of breath support in projection of the singing voice. Journal of Voice. n.1, v.15, p.86-104.

33. TITZE, I. (2004). What makes a voice acoustically strong? Journal of Singing. n.1, v.61, p.63-64. 
Notas sobre as autoras

Nadja Barbosa de Sousa é Cantora lírica, Bacharel em Música/Canto pela Universidade Federal de Pernambuco (UFPE), Mestre e Doutora em Fonoaudiologia pela Pontifícia Universidade Católica de São Paulo (PUC-SP), com período Sanduíche na Alemanha, na Hochschule für Musik und Darstellende Kunst Frankfurt am Main (Faculdade de Música e Artes Cênicas de Frankfurt), como bolsista CAPES (PDSE). Exintegrante do Coral Lírico do Theatro Municipal de São Paulo-SP.

Marta Assumpção de Andrada e Silva é Fonoaudióloga, Mestre em Distúrbios da Comunicação pela Pontifícia Universidade Católica de São Paulo (PUC-SP), Doutora em Comunicação e Semiótica pela PUC-SP, Professora no Programa de Estudos Pósgraduados em Fonoaudiologia da PUC-SP e professora adjunta da Graduação em Fonoaudiologia na Faculdade de Ciências Médicas da Santa Casa de São Paulo (FCMSCSP). 